\title{
The Impact of CS for All on College Placement in Computer Science
}

\author{
Ronald I. Greenberg \\ Loyola University Chicago \\ Chicago, Illinois \\ rig@cs.luc.edu
}

\author{
Julie Medero \\ Harvey Mudd College \\ Claremont, California \\ julie@cs.hmc.edu
}

\author{
Samuel A. Rebelsky \\ Grinnell College \\ Grinnell, Iowa \\ rebelsky@grinnell.edu
}

\author{
Frances P. Trees \\ Rutgers University \\ Piscataway, New Jersey \\ fran.trees@cs.rutgers.edu
}

\author{
Dale Reed (moderator) \\ University of Illinois at Chicago \\ Chicago, Illinois \\ reed@uic.edu
}

\begin{abstract}
With the CS for All movement increasingly gaining traction nationally, students entering colleges and universities are arriving with deeper and broader CS experiences. This in turn can change students' higher education starting point. This panel of CS faculty with expertise in this area will present perspectives and models to describe how higher education choices for placement, credit, and curriculum design affect the efforts to broaden participation in student pathways into computing and related studies.
\end{abstract}

\section{CCS CONCEPTS}

- Social and professional topics $\rightarrow$ Model curricula; Computing education programs; Student assessment.

\section{KEYWORDS}

computer science placement; programming prerequisites; computing pathways; CS for All

\section{ACM Reference Format:}

Ronald I. Greenberg, Julie Medero, Samuel A. Rebelsky, Frances P. Trees, and Dale Reed (moderator). 2020. The Impact of CS for All on College Placement in Computer Science. In The 51st ACM Technical Symposium on Computer Science Education (SIGCSE '20), March 11-14, 2020, Portland, OR, USA. ACM, New York, NY, USA, 2 pages. https://doi.org/10.1145/3328778. 3366968

\section{SUMMARY}

The growth of AP CS Principles and national efforts to offer and require more CS courses has resulted in an increased number of students arriving at colleges and universities having already taken one or more high school or community college CS courses or having informal education experiences in computing. Colleges and universities are then faced with choices of whether or not to use this experience for placement or for elective/general-education/major credit. Many institutions assume a level of computer proficiency

Permission to make digital or hard copies of part or all of this work for personal or classroom use is granted without fee provided that copies are not made or distributed for profit or commercial advantage and that copies bear this notice and the full citation on the first page. Copyrights for third-party components of this work must be honored.

For all other uses, contact the owner/author(s).

SIGCSE '20, March 11-14, 2020, Portland, OR, USA

(C) 2020 Copyright held by the owner/author(s)

ACM ISBN 978-1-4503-6793-6/20/03.

https://doi.org/10.1145/3328778.3366968 and literacy, while others have placement exams, similar to what is done in English and Mathematics.

The institutional choices made in navigating this terrain can serve to either discourage or encourage female, Black, and Latinx students, the very ones that have historically been disenfranchised by the predominantly white male culture in CS. As SIGCSE community high school and higher education teachers interested in broadening participation in computing, we want students to get credit for work and learning already done, and we want students to be placed into appropriate subsequent courses. Our discussion will deepen and generalize that of a previous panel [1].

\section{PANEL STRUCTURE}

The panel will start with a presentation of three very brief student stories, illustrating the challenges and differences in the experiences of students making the transition from high school or community college into four-year institutions. (5 minutes)

Audience members will then be invited in groups of $\approx 3$ to briefly exchange their own stories with each other on how CS placement and credit has worked in their own lives and in the lives of their students. (5 minutes)

The four panelists will then each introduce themselves and have three slides each: $(4 \times 6$ minutes $=24$ minutes $)$

(1) Overview of their institution and student demographics

(2) Summary of their institution's handling of CS placement/credit

(3) Highlights of successes and challenges with regard to broadening participation

Audience participants will again confer in groups of 3 to exchange observations and questions. Questions will be received verbally as well as through Google Slides Q\&A, which allows audience members to up-vote questions of common interest.(35 minutes)

In closing the panelists will offer recommendations from their own experience on the highest leverage practice(s) for placement and credit that they have found to be helpful in broadening participation in CS.(6 minutes)

\section{RONALD I. GREENBERG}

Ron Greenberg is a Professor of Computer Science at Loyola University Chicago and Undergraduate Program Director for the CS Department. Loyola offers multiple computing majors (with about 
275 students), as well as interdepartmental majors and various minors. All require some computer programming, and placement of incoming students has presented increasing challenges.

The emerging approach at Loyola is to tighten prereqs for the first programming-intensive course, COMP 170, but allow students needing to start in a gentler programming course (combined with other introductory CS content), COMP 150, to count that course towards the major. We view this as an approach that both maintains sufficient rigor and also provides welcoming opportunities to students lacking preparatory privilege. The approach resembles use of a strict prerequisite for entry to the calculus sequence in mathematics majors and the granting of college credit for the prerequisite course but differs in the allowance of this credit in the major.

For placement into COMP 170 versus COMP 150, we accept students who have taken any prior college-level programming course. and explicitly state "or permission" as part of the COMP 170 prereqs; if a student has taken a high school programming course or can describe other substantive programming experience, we cannot grant credit but will waive the student into COMP 170 . We also allow students who have taken a college-level calculus course; our experience has generally shown the course can be handled by students who have the comfort with abstraction and logic that generally comes at this level of mathematical sophistication.

\section{JULIE MEDERO}

Julie Medero is an Assistant Professor of Computer Science at Harvey Mudd College (HMC), a small undergraduate institution that is part of the Claremont Colleges consortium. The CS department at HMC serves three majors. Overall, 550 students take an HMC intro CS course each year, 200 complete our third semester data structures course, and 140 graduate with one of the CS-related majors.

HMC requires all first semester students take an intro CS course. Additional sections are offered in the spring for other consortium students. All of the intro courses offer a breadth-first introduction to the field, from digital logic through proofs of uncomputability.

No credit or testing out is offered. Instead, four different intro course are offered, with a goal of placing each student in a course that will be both challenging and welcoming. Three of these are "flavors" of CS1 course: one for students with little or no experience, one for students with approximately one year of formal CS study, and one that presents all content in a computational biology context. The fourth combines CS1 and CS2 into a single semester.

With more students getting CS experience before college, writing, administering, and grading placement tests takes more faculty time. The department now directly places students with a 4 or a 5 on the AP CS A exam in the CS1 course for students with prior experience. Students who have taken AP CS Principles are encouraged to take the version of CS1 for students with little or no prior experience, since most of that content will still be new to them.

\section{SAMUEL A. REBELSKY}

Sam Rebelsky is Professor and former Chair of Computer Science at Grinnell College, a small (1700 student) highly selective liberal arts college. Grinnell's curriculum is listed as an exemplar in the CS2013 ACM curriculum guidelines. We graduate over 60 majors per year, a four-fold increase over five years ago. Our greatest concerns in placement issues relate to equity and inclusion. In spite of great strides, "CS for All" still means "CS for Some" and, too often, many of those who are underrepresented in computing feel that they are at a disadvantage. Placing students with prior background in a more advanced course highlights these differences and, in effect, creates two communities of students. However, we also worry that putting all or most students in the same course can also highlight differences.

We continue to rely on the model we have used for the past two decades: Almost all students start in a workshop-style course that emphasizes a functional approach. The functional language helps level the playing field; students with experience in other languages not only find the syntax of functional languages different, they must rethink their approach to problem solving as they do without assignment, use recursion rather than iteration, and employ higherorder operations. At the same time, the pair-programming pedagogy develops community and builds respect for different skill sets.

As the percentage of students with prior background rises, while the inequities in who has that background persist, our current approach is being tested. We continue to consider both modifications to our current strategy and new strategies.

\section{FRANCES P. TREES}

Fran Trees is a Teaching Professor and the Director of Undergraduate Introductory Instruction for non-majors for the Department of Computer Science at Rutgers, The State University of NJ. The Department services approximately $150 \mathrm{PhD}$ students, 225 students enrolled in one of the two Masters Programs, and approximately 1,325 declared undergraduate majors, where we are currently showing a $12 \% 1$-year growth, and a $251 \% 5$-year growth. CS Minors are growing at an even higher rate.

Our CS program is traditional in nature, requiring 11-13 CS courses, 3 math courses, and 2 physics or chemistry courses. Our CS1 course is taught using Java and enrolls $\approx 1600$ students per year. Students in this course have very diverse programming backgrounds. We currently do not have honors sections but are actively pursuing this and other strategies to offer more challenge for students arriving with a strong CS background. We attempt to help level the playing field in CS1 by focusing on writing structured pseudocode to solve problems for the first two weeks before introducing any Java programming environment. We also provide support systems for struggling students, allowing students to help design their own collaboration and group work environments, and providing undergraduate near-peer tutoring. Although our nonmajors CS courses reflect the diversity of the university, our ethnic and gender representations in the CS courses for majors do not. CS for ALL? Not really. We are very slowly narrowing the gender gaps in CS1 (up to 27\%) but not in the subsequent courses $(<20 \%)$.

\section{ACKNOWLEDGMENTS}

Authors are supported in part by National Science Foundation grant numbers 1738515, 1738691, 1659805, and 1837305.

\section{REFERENCES}

[1] Crystal Furman, Owen Astrachan, Daniel D. Garcia, David Musicant, and Jennifer Rosato. 2019. CS Principles Higher Education Pathways. In SIGCSE '19. Association for Computing Machinery, 498-499. 